\title{
LAICIDADE, TOLERÂNCIA E EDUCAÇÃO: UM ESTUDO SOBRE REPRESENTAÇÕES SOCIAIS DE PROFESSORES NA REDE PÚBLICA EM UM MUNICÍPIO NO INTERIOR PERNAMBUCANO
}

\author{
PhABLo Freire \\ Faculdade de Ciências Humanas e Exatas do Sertão do São Francisco \\ (FACESF), Belém do São Francisco, Pernambuco, Brasil \\ Amanda Matos do Nascimento \\ Faculdade de Ciências Aplicadas e Sociais de Petrolina (FACAPE), \\ Petrolina, Pernambuco, Brasil
}

\begin{abstract}
REsUmo: O presente artigo objetiva analisar a percepção de professores em escolas públicas sobre a laicidade, com vistas a discutir a experiência do espaço público e como é construída a tolerância social a partir dessas trocas simbólicas. Como instrumento de coleta, utilizou-se um roteiro semiestruturado, sendo adotada a análise de conteúdo temático para apreciação do material. Concluiu-se que os respondentes representam a laicidade e a tolerância como fenômenos dissociados, entendendo a laicidade como existente, com status de fenômeno jurídico-formal, sem um correspondente social concreto, enquanto a tolerância é significada como socialmente inexistente, convertendo-se a laicidade em norma simbólica nas modalidades confirmação de valores e legislação-álibi, configurando-se como óbice para a superação dos contextos de intolerância social marcada pelo elemento religioso.
\end{abstract}

Palavras-chave: Laicidade. Ensino público. Constitucionalismo simbólico. Representações sociais.

INTRODUÇÃO

A sociedade brasileira é marcada pela diversidade cultural e a sua população carrega traços de miscigenação de diversos povos. Sendo assim, são inúmeros os hábitos e costumes arraigados ao modo de viver e conviver em comunidade. No entanto, o repertório cultural europeu influenciou profundamente o processo de formação da nação, determinada, sobretudo, pela hegemonia católica, operando uma colonização do modo de vida por signos privados. Nos domínios culturais, dado o traço hegemônico mencionado, não ocorreu, desde a formação nacional, qualquer estímulo para que o convívio com o diverso se desse de forma horizontal, de modo a superar os traços de discriminação e exclusão, desde sempre presentes na sociedade brasileira, persistindo até 
nossos dias um senso de superioridade de determinados grupos e seus traços culturais privados em relação a outros.

Nesse contexto se insere a problemática acerca dos limites da laicidade no Brasil, sendo importante discutir como se opera sua efetividade nos espaços públicos e o quanto esse signo jurídico pode afetar a dinâmica interacional dos indivíduos, uma vez que na Constituição Federal de 1988, assim como suas antecessoras, determina a condição laica do Estado.

Assim sendo, o presente artigo objetiva analisar a percepção de agentes públicos em escolas públicas sobre a laicidade e a tolerância, com vistas a discutir a atuação profissional para formação da consciência cidadã, a experiência do espaço e agir público e como, a partir dessas relações, é construída a tolerância social.

A respeito das questões metodológicas, o atual estudo empírico caracteriza-se como qualitativo interdisciplinar do tipo jurídico-descritiva (GUSTIN; DIAS, 2013), valendo-se do aporte teórico-metodológico das representações sociais para construção do corpus da pesquisa. O controle metodológico dos dados e conclusões se deu por meio da triangulação teórica elegendo-se três eixos para análise: 1. Constitucionalismo simbólico; 2 . Teorias de Laicidade e tolerância; 3 . Teoria das representações sociais.

\section{APORTE TEÓRICO E NORMATIVO}

\subsection{CONSTITUCIONALISMO SIMBÓLICO EM MARCELO NEVES}

Ao discutir os níveis de relevância jurídico-instrumental das constituições, a saber, a capacidade de concretização normativa do conteúdo textual, Neves (1996) aponta para dois tipos de constituições: as constituições normativas e as simbólicas. No primeiro tipo, "a constituição funciona realmente como instância reflexiva de um sistema jurídico vigente e eficaz" (p.326), de maneira que, a despeito de seu presente caráter simbólico, ele não é capaz de esvaziar a normatividade esperada pela normatividade constitucional. De outro modo, quando do tipo simbólico, a constituição apresenta uma dissociação entre a emissão do texto constituinte e a normatividade jurídica generalizada, obstruindo assim uma abrangente concretização normativa constitucional. Dessa maneira, cresce a distância entre a efetividade da norma e sua qualidade simbólica em razão do crescente simbolismo ou, como conceitua o autor, pela "hipertrofia da dimensão simbólica em detrimento da realização jurídico-instrumental dos dispositivos constitucionais" (p.326).

Deste modo, ao apresentar-se como rico arcabouço normativo, todavia esvaziado de possível efetividade - como consequência da hipertrofia simbólica -, a constituição acaba por figurar como instrumento ideológico, quando desconecta a sociedade para qual se dirige das possibilidades de concreta transformação. Isso porque a constituição simbólica obstrui a potencialidade de mudança social quando, por meio de sua condição discursiva: 1. opera distinções sociais ao selecionar indevidamente valores de grupos específicos; 2 . desloca a responsabilidade do Estado em promover alterações estruturais ao anunciar os processos como já normatizados; 3. dilata para um futuro incerto a possibilidade de implementação das promessas por ela veiculadas. Tais efeitos 
desdobrados dos processos simbólicos são categorizados por Neves (2011) em três tipos: 1. confirmação de valores, 2. legislação-álibi e 3. fórmula de compromisso dilatório.

Assim, considerando o interesse da presente pesquisa, é possível evocar as promessas erigidas na Constituição de 1988, isto é, os axiomas que orientam os ideais das liberdades laicas, a igualdade, o princípio e a garantia da laicidade, mais especificamente: a liberdade de consciência e de crença (art.5\%, VI, primeira parte, CF), o livre exercício dos cultos religiosos (art. $5^{\circ}, \mathrm{VI}$, segunda parte, $\mathrm{CF}$ ), a proteção aos locais de culto e a suas liturgias (art. $5^{\circ}, \mathrm{VI}$, última parte, $\mathrm{CF}$ ), o direito à prestação de assistência religiosa nas entidades civis e militares de internação coletiva (art. $5^{\circ}, \mathrm{VII}, \mathrm{CF}$ ), a não privação ou cerceamento de direitos em razão do elemento religioso (art. $5^{\circ}$, VIII, primeira parte, CF), a erradicação da marginalização e redução das desigualdades sociais marcadas ou determinadas pelo elemento religioso (art. $3^{\circ}, \mathrm{III}, \mathrm{CF}$ ) e, finalmente, a igualdade entre os indivíduos (art. 5०, caput, CF). Podendo todo esse conteúdo ter sua (in)efetividade discutida a partir do marco teórico do simbolismo constitucional e seus efeitos.

\subsection{LAICIDADE, TOLERÂNCIA E ESFERA PÚBLICA NAS ESCOLAS}

O contexto histórico que introduz no ocidente o modelo de Estado laico se identifica com o processo político, jurídico e social moderno que restou, sendo conhecido como secularização. Assim, de acordo com Catroga (2010, p.62), "não se errará muito se se defender que o conceito de secularização passou a conotar a perda, nas sociedades modernas ocidentalizadas, da posição-chave que a religião institucionalizada ocupava na produção e na reprodução do elo social e na atribuição do sentido (à vida social)". Dessa forma, as Igrejas cristãs, sobretudo a católica - símbolo de supremacia e poder dominante no mundo ocidental -, decaem daquela posição soberana em uma sociedade que se levanta contra as descriminalizações institucionalizadas. Simultaneamente, os mecanismos de controle do Estado, quando pautados pelo dogma religioso, começam a ser socialmente questionados. Neste sentido, é pertinente afirmar que a secularização da sociedade implicou numa mudança do eixo legitimador estatal, outrora exclusivamente religioso, para elaboração de um modo outro de Estado, pautado no interesse dos indivíduos e na racionalização da vida social, configurando o conteúdo religioso como elemento da esfera privada da vida social e, em seguida, operando a separação entre interesses privados e públicos.

Ao discorrer sobre o conceito de laicidade, Blancart $(2008$, p.19) afirma se tratar de "um regime social de convivência, cujas instituições políticas estão legitimadas principalmente pela soberania popular e já não mais por elementos religiosos", devendo ser elaborada uma autonomia do Estado em relação àquilo que se compreende como interesses privados. Sendo essa condição autônoma referente à produção de outro tipo de interesse, o comum, diferente daquele estritamente individual. Nesse mesmo sentido, ao buscar uma conceituação para a esfera pública, Pena-Ruiz (2003) distingue os conteúdos privados e públicos, asseverando que, em termos jurídicos, deve ser entendido como público tudo aquilo que, indubitavelmente, for relativo ou pertinente a todos os indivíduos de uma comunidade política, enquanto privados são aqueles conteúdos, ou razões, de interesses específicos de indivíduos ou grupos, livremente associados, sendo as religiões um dos mais claros exemplos de conteúdos privados. $O$ autor ainda chama a atenção para o fato de que as religiões podem possuir uma dimensão coletiva - elemento 
frequente, com efeito - todavia, este não deve ser confundido com o status de coisa pública. Isto porque, públicos serão aqueles conteúdos que efetivamente interessem a toda coletividade (religiosa ou não).

Assim, enquanto a secularização configura-se como o processo de saída do religioso desse intervalo de confusão - quando a esfera pública é colonizada pelo interesse de um credo especifico cerceando os demais modos de vida, alterando as bases legitimadoras estatais - a laicidade funciona como processo de manutenção e mensuração dos níveis de equilibro nas relações atravessadas pelo elemento religioso. Sendo, com efeito, tais processos analíticos contínuos de alta relevância nas sociedades cujas estruturas sociais anteriores aos processos democratizantes foram determinadas pelo conteúdo religioso.

Nisso, segundo Pena-Ruiz (2003), a mensuração da laicidade - uma laicidade estrita - guarda relação direta com a experiência social tolerante no tocante a estas três dimensões: 1 . liberdade de consciência; 2 . igualdade entre cidadãos; 3 . neutralidade na atuação estatal na busca do bem comum. A primeira das dimensões, a liberdade de consciência, é observada na capacidade dos indivíduos e grupos experimentarem a autoderminação para a experiência da vida civil, ou seja, a possibilidade de autopercepção no tocante às condições necessárias para a dinâmica social de exercício de direitos. De acordo com Lane (1989), o conceito de consciência está diretamente relacionado com a ideia de desnaturalização dos processos sociais que interpelam os indivíduos e os constituem socialmente, além das condições que afetam suas relações sociais e posições de poder. Desse modo, quando desconhecedores dos fatores que determinam as condições de sua experiência social, encontram-se impedidos de se dirigir para a mudança social, logo, não experimentam a consciência. Essa ausência do saberes suficientes sobre os processos constitutivos sociais caracteriza a condição do indivíduo como alienado.

De acordo com Pena-Ruiz (2003), o indivíduo que se encontra sem o livre exercício da liberdade de consciência não pode, plenamente, determinar sua existência e atuação social, permanecendo, segundo Lane (1989), alienado dos meios que o constituem socialmente, de modo que, nestas condições, fica impedido de perceber as desigualdades que o atravessam, por isso, encontra-se cerceado na segunda condição da laicidade, a igualdade entre os cidadãos.

A igualdade entre os cidadãos, como aduz Pena-Ruiz (2003), é percebida na capacidade de simétricas condições de atuação em sociedade, em posições de poder equivalentes entre os indivíduos ou pela possibilidade de luta e reconhecimento na produção dessa igualdade. Todavia, como mencionado, quando indivíduos e grupos se encontram alienados, inviabiliza-se sua possibilidade de luta pela produção de uma condição isonômica. Sem liberdade ou exercício de consciência não há que se falar em igualdade e, sem ambas, não há laicidade, sendo precisamente nesse intervalo que se verifica, como aponta Pena-Ruiz (2003), a importância da neutralidade estatal, isto é, uma atuação estatal em direção à alteração dessas dinâmicas alienantes.

Para o pensador francês, a neutralidade, no tocante às questões laicas, é o agir ou o não agir estatal voltado à produção ou manutenção da liberdade de consciência e da igualdade entre os cidadãos, noutros termos, quando o convívio social possibilita aos 
indivíduos a experiência da liberdade de consciência e a partir dela sua atuação para produção da igualdade. Não deve o Estado intervir criando óbice a estas circunstâncias, na mesma medida, quando ausentes tais condições, deve o Estado atuar para providenciar a correção de tais realidades. Quando deve agir o Estado e este não o faz, fere a neutralidade e deixa de ser laico, ao passo que, atuando contra a liberdade de consciência e impossibilitando a igualdade entre os indivíduos, ele deixa, da mesma forma, de ser laico, por afastar-se de uma posição neutra.

Conforme Pena-Ruiz (2003), apenas quando o Estado reúne os três pressupostos supracitados, torna-se possível afirmá-lo como laico, sendo a inexistência de tais condições sociais em face da existência de previsão normativa para uma suposta laicidade, uma mera afirmação jurídica, ou seja, uma laicidade simbólica, uma vez que se encontra desacompanhada de efetividade social, um instrumento ideológico de manutenção de realidades sociais desiguais.

Acompanhando esses debates, na perspectiva de Zarka (2013), a tolerância social é reflexo de um Estado que implementa políticas públicas especificas para produção do convívio social. Dessa maneira, seria compreendida como tolerância a "virtude mínima na qual o seu valor está em assegurar a coexistência dos indivíduos, dos grupos ou dos povos diferentes, os quais são até mesmo opostos entre si" (ZARKA, 2013, p.31). Essa virtude, segundo o autor, é um produto de intervenções públicas dirigidas pelo Estado e pela sociedade, uma vez que, sozinhos, os indivíduos não estariam aptos a condicionarem suas relações para o convívio igualitário e pacífico, sendo a educação, com efeito, o instrumento mais apropriado para produção destes efeitos sociais laicos e, por consequência, tolerantes.

\subsection{ENSINO LAICO NO BRASIL}

O ensino brasileiro encontra previsão normativa na Constituição Federal, em seu art. 205, em que a educação é disciplinada como direito coletivo direcionado a todos e, por sua vez, dever do Estado e responsabilidade da família e sociedade, com vistas ao pleno desenvolvimento da pessoa, do exercício da cidadania e qualificação para o trabalho. No art. 206 do texto constitucional, são encontrados os princípios norteadores da educação, tais como a igualdade de condições para o acesso e permanência na escola, liberdade de aprender, ensinar, pesquisar e divulgar o pensamento, a arte e o saber; pluralismo de ideias e de concepções pedagógicas e coexistência de instituições públicas e privadas de ensino.

Desta forma, os artigos citados evidenciam os três principais objetivos da educação, quais sejam: a evolução dos indivíduos enquanto participantes da sociedade, o desenvolvimento das competências de exercício do papel cidadão e, por fim, a capacidade de adentrar no mercado de trabalho. Mais especificamente, encontra-se no art. 210 disposições referentes ao ensino fundamental, relacionadas com a formação básica comum e o respeito aos valores culturais e artísticos nacionais e regionais. Assim, no $\S 1^{\circ}$ do aludido artigo, o ensino religioso é mencionado como disciplina a ser ofertada mediante matrícula facultativa e em horários regulares nas escolas públicas de ensino fundamental. 
A Lei de Diretrizes e Bases da Educação Nacional (Lei n. 9.394/1996, LDB) também possui em seus artigos disposições sobre o ensino religioso em escolas públicas de ensino fundamental, nos seguintes termos:

Art. 33. O ensino religioso, de matrícula facultativa, é parte integrante da formação básica do cidadão e constitui disciplina dos horários normais das escolas públicas de ensino fundamental, assegurado o respeito à diversidade cultural religiosa do Brasil, vedadas quaisquer formas de proselitismo.

$\S 1^{\circ}$ Os sistemas de ensino regulamentarão os procedimentos para a definição dos conteúdos do ensino religioso e estabelecerão as normas para a habilitação e admissão dos professores.

$\S 2^{\circ}$ Os sistemas de ensino ouvirão entidade civil, constituída pelas diferentes denominações religiosas, para a definição dos conteúdos do ensino religioso.

A respeito da temática, laicidade e ensino religioso nos espaços públicos, é pertinente mencionar um acordo firmado entre a Igreja Católica e o Estado brasileiro, que ficou conhecido como 'concordata de $2010^{\prime \prime}$, tratando de diversos assuntos, sendo um deles o ensino religioso nas escolas públicas. Em seu art. 11, o documento dispõe:

Art. 11 A República Federativa do Brasil, em observância ao direito de liberdade religiosa, da diversidade cultural e da pluralidade confessional do País, respeita a importância do ensino religioso em vista da formação integral da pessoa.

$\$ 1^{\circ}$. O ensino religioso, católico e de outras confissões religiosas, de matrícula facultativa, constitui disciplina dos horários normais das escolas públicas de ensino fundamental, assegurado o respeito à diversidade cultural religiosa do Brasil, em conformidade com a Constituição e as outras leis vigentes, sem qualquer forma de discriminação.

A mencionada disposição contraria 0 art. 33 da LDB, que determina que 0 conteúdo da disciplina ensino religioso seja estabelecido pelos sistemas de ensino, depois de ouvidas entidades civis, constituídas pelas diversas confissões religiosas. Nesse sentido, Faria e Ferreira (2012) afirmam que nos estados laicos existe um comprometimento do Estado de respeito à liberdade religiosa e à diversidade de crenças e cultos. Assim, a neutralidade implica rejeição de uma religião oficial e, consequentemente, na ausência de regalias e privilégios para qualquer culto especifico. Como destaca o autor, o afastamento do Estado de preferencias religiosas não coloca de lado ou compromete a religiosidade de seus cidadãos, uma vez que a estes caberá decidir e implementar os meios necessários à realização de suas respectivas crenças.

\subsection{TEORIA DAS REPRESENTAÇÕES SOCIAIS (TRS)}

De acordo com Jodelet (2001, p.22), o conceito de representação social (RS) diz respeito a "uma forma de conhecimento, socialmente elaborada e partilhada, com um objetivo prático, e que contribui para a construção de uma realidade comum a um conjunto social", ou seja, aqueles conjuntos de saberes, organizados, estruturados e partilhados socialmente, sendo capazes de orientar as condutas dos grupos e indivíduos. 
FREIRE, P.; NASCIMENTO, A. M.

Nisso, uma RS, ao figurar socialmente como um saber instrumental sobre o mundo, sendo então possível conceber, como sugerem Santos e Almeida (2005, p.34), ao menos quatro funções para as RS: 1 . Significara realidade social, de maneira que os atores sociais possam compreendê-la e articulá-la; 2. Orientar as práticas e comunicações sociais; 3. Estabelecer um sistema de referências justificador de comportamentos e 4. Produzir identidades, na medida em que afeta os papeis socialmente vivenciados.

Dessa forma, como aponta Sá (1998), a compreensão sobre o comportamento político dos grupos, sobretudo o exercício da cidadania, a saber, a tomada de posição dos indivíduos em sociedade frente às realidades que os interpelam e os afetam, atravessa a compreensão sobre suas RS, uma vez que para entender como os atores agem ou permanecem inertes em suas interações sociais é preciso conhecer como eles significam tais posicionamentos.

\section{MÉTODO}

\subsection{PARTICIPANTES}

Para a pesquisa, foram selecionados 39 indivíduos, profissionais ligados à educação em escolas públicas no município de Petrolina-PE, sendo eles 34 professores, 3 diretores, 1 coordenador e 1 pedagogo (14 homens e 25 mulheres), com idade média de 42 anos (entre 22 e 60 anos). A amostra é de natureza não probabilística intencional, levando-se em conta como critério de inclusão a condição de educador, e como critérios de exclusão, a atuação profissional exclusiva em escolas públicas, especificamente no ensino médio. Para o fechamento da amostra, foi utilizado o critério da saturação.

\subsection{PROCEDIMENTO DE COLETA E INSTRUMENTO}

A coleta de dados se deu no próprio ambiente das Escolas Públicas no aludido município, no primeiro semestre de 2017 , sendo as entrevistas norteadas por um roteiro semiestruturado, elaborado a partir dos elementos teóricos identificados para laicidade e tolerância. Os procedimentos foram autorizados mediante informe e assinatura do Termo de Consentimento Livre e Esclarecido (TCLE), durante os intervalos das aulas, na sala dos professores das respectivas instituições.

\subsection{ANÁLISE DOS DADOS}

O corpus da pesquisa, resultado de todo o material coletado e transcrito, foi apreciado por meio da análise de conteúdo temático de Bardin (2002), possibilitando assim a identificação dos conteúdos centrais das mensagens veiculadas pelos respondentes. Tal método foi implementado através de três etapas, sendo a primeira delas, a leitura flutuante que se configura como uma pré-análise do material a disposição dos pesquisadores, com vistas a sistematização dos temas evocados, seguindo-se da exploração do material, que ocorre com a categorização das ideias emergentes passandose, finalmente, à interpretação dos dados a partir das teorias selecionadas. 


\section{RESULTADOS E DISCUSSÕES}

Três eixos de análise foram agrupados a partir do conteúdo analisado: I. Laicidade; II. Tolerância; e III. Enfrentamento da intolerância, de modo que os resultados serão apresentados nas tabelas dispostas a seguir.

Tabela 1 - Representação social de laicidade para os profissionais em educação

\begin{tabular}{|c|c|c|c|}
\hline Categoria & $f$ & Categoria & $f$ \\
\hline 1. Inexistência da laicidade material & 49 & 3. Conteúdo social alaico & 14 \\
\hline Na prática não é laico & 12 & Ainda há muito preconceito & 8 \\
\hline Não existe respeito (entre culturas) & 14 & 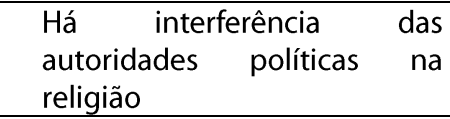 & 4 \\
\hline $\begin{array}{l}\text { Uma crença (católica) se sobrepõe as } \\
\text { demais }\end{array}$ & 4 & $\begin{array}{l}\text { Liberdade restrita aos católicos } \\
\text { e evangélicos }\end{array}$ & 1 \\
\hline $\begin{array}{l}\text { Há interferência religiosa na } \\
\text { educação }\end{array}$ & 4 & Não há neutralidade & 1 \\
\hline $\begin{array}{lll}\begin{array}{l}\text { Feriados religiosos } \\
\text { contradição laica) }\end{array} & \text { (como } \\
\end{array}$ & 2 & & \\
\hline Há religião nos espaços públicos & 2 & & \\
\hline $\begin{array}{l}\text { Grau de laicidade depende de cada } \\
\text { município }\end{array}$ & 2 & & \\
\hline Não aceitação da opinião diversa & 1 & & \\
\hline $\begin{array}{l}\text { Necessidade de educação para } \\
\text { tolerância }\end{array}$ & 1 & & \\
\hline Mudança depende de base familiar & 1 & & \\
\hline Foco na religião & 1 & & \\
\hline Há muita intolerância & 1 & & \\
\hline Há intolerância implícita & 1 & & \\
\hline Discriminação de religiões e raças & 1 & & \\
\hline $\begin{array}{l}\text { Bancada evangélica } \\
\text { contradição laica) }\end{array}$ & 1 & & \\
\hline Minoria discriminada & 1 & & \\
\hline $\begin{array}{l}\text { 2. Laicidade na lei (meramente } \\
\text { formal) }\end{array}$ & 19 & 4. Outros & 3 \\
\hline Há, constitucionalmente falando & 16 & & \\
\hline $\begin{array}{l}\text { É dada a liberdade individual às } \\
\text { pessoas (pela lei) }\end{array}$ & 2 & & \\
\hline $\begin{array}{l}\text { Não há interferência (do Estado) nas } \\
\text { questões religiosas }\end{array}$ & 1 & & \\
\hline
\end{tabular}

Como se observa na Tabela 1, a partir das questões disparadoras: "o que é a laicidade?" e "o Brasil é um pais laico?", buscou-se identificar quais sentidos sobre a laici- 
FREIRE, P.; NASCIMENTO, A. M.

dade eram compartilhados entre os respondentes, de maneira que o conteúdo foi agrupado em três categorias principais: 1 . Inexistência de laicidade material $(\mathrm{n}=49) ; 2$. Laicidade na lei (meramente formal) $(n=19) ; 3$. Negativa da existência para laicidade $(n=14)$. As respostas agrupadas na categoria Inexistência de laicidade material deixam entrever sentidos vinculados à ideia de uma contradição social evidente para o constructo laico, por meio de expressões como:

Teoricamente eu acho que sim, na prática eu já não acho [...] Sim, na Constituição o estado brasileiro é laico, na prática não tem sido [...] Há interferência religiosa na educação [...] Há muita intolerância (DADOS DA PESQUISA, 2017).

O sentido contraditório visto acima, quando analisado isoladamente, ou seja, o conteúdo da fala dos respondentes, evidencia uma característica especifica dos fenômenos jurídicos, a saber, a dicotomia entre o dever ser e o ser. Isso porque, quando delimitados determinados fenômenos a partir das normas jurídicas (dever ser), é possível que a realidade social (ser) não encontre total correspondência, de maneira que a observação dessa correspondência implica numa maior ou menor efetividade, como pontua Barroso (2001). Logo, quando afirmam que o Estado é laico, mas demonstram condições sociais contrárias à laicidade, estão tratando a condição formal da laicidade (dever ser) em face das condições materiais desta mesma laicidade (ser), isto é, sua efetividade.

A segunda categoria mais evocada, Laicidade na lei (meramente formal), traz sentidos que derivam da assertiva "sim, existe laicidade...", no entanto, os sentidos dessa categoria buscam dar conta de uma percepção afirmativa, aproximando-se da ideia de existência a partir da previsão formal, por meio de enunciados como:

na lei em sim, acho que sim [...] Na constituição é laico, então é laico sim [...] a constituição coloca que sim, que você pode expressar a religião que quiser [...] Sim, dentro da Constituição Federal de 1988, garante isso. No entanto a gente vê de vez em quando, desembargadores, promotor de justiça, juiz, parlamentares de todas as esferas, terem atitudes que vão de contra a essas garantias (DADOS DA PESQUISA 2017).

Tendo em vista que a dicotomia ser e dever ser acompanha todos os fenômenos jurídicos, a distinção de conteúdos entre a categoria 1 e 2 repousa no fato de que a categoria 2 carrega sentido que evidencia o lugar da laicidade, isto é, a perspectiva de que a laicidade pode ser encontrada na lei, a despeito de haver ou não um correspondente social. A proximidade entre as duas categorias veicula sentidos de que o Brasil é um país laico, porém tal laicidade não é encontrada na experiência social.

Uma terceira categoria foi nomeada como conteúdo social alaico, em razão de veicular traços de uma dinâmica social marcada por violações à laicidade. Sem qualquer conexão com a formalidade legal, a categoria veicula características da experiência social opostas ao ideal laico. Tais sentidos se organizaram a partir de sentenças iniciadas com uma ideia de negação exemplificada pela assertiva "não, não há laicidade", seguida de elementos fáticos. 
O segundo eixo de análise buscou os sentidos socialmente partilhados pelo grupo para a tolerância no convívio social. Cinco categorias foram agrupadas a partir do conteúdo presente nas falas, como se observa na Tabela 2:

Tabela 2 - Representações sobre a tolerância social

\begin{tabular}{|c|c|c|c|}
\hline Categoria & $f$ & Categoria & $f$ \\
\hline 1. Inexistência da tolerância & 59 & $\begin{array}{l}\text { 2. Necessidade de educação para } \\
\text { tolerância }\end{array}$ & 12 \\
\hline Não existe tolerância & 10 & $\begin{array}{l}\text { Não estamos preparados para } \\
\text { tolerância }\end{array}$ & 3 \\
\hline Sociedade é intolerante & 8 & $\begin{array}{l}\text { Educação é insuficiente para } \\
\text { tolerância }\end{array}$ & 2 \\
\hline Não existe respeito & 6 & $\begin{array}{l}\text { Sem educação vamos ter pessoas } \\
\text { intolerantes }\end{array}$ & 2 \\
\hline $\begin{array}{l}\text { Podemos tolerar até certo ponto }\left(1^{\mathrm{a}}\right. \\
\text { acepção) }\end{array}$ & 6 & É necessário políticas públicas & 2 \\
\hline Há preconceito velado & 4 & É preciso aprender a ser tolerante & 1 \\
\hline Há preconceito & 3 & Aprender a respeitar a diferença & 1 \\
\hline Intolerância está oculta & 3 & $\begin{array}{l}\text { Falta formação para o professor } \\
\text { (em questões de tolerância) }\end{array}$ & 1 \\
\hline $\begin{array}{l}\text { Escutamos sobre intolerância nos } \\
\text { noticiário }\end{array}$ & 3 & & \\
\hline Conservadorismo vem à tona & 2 & & \\
\hline $\begin{array}{l}\text { Há intolerância quanto à cor, opção } \\
\text { sexual, religião, social }\end{array}$ & 2 & & \\
\hline Intolerância é histórica & 2 & & \\
\hline Há desrespeito da lei & 1 & & \\
\hline É difícil o convívio social & 1 & & \\
\hline Não é como deveria ser & 1 & & \\
\hline É laico, mas o calendário é religioso & 1 & & \\
\hline Não é fácil aceitar a religião do outro & 1 & & \\
\hline A religião condiciona & 1 & & \\
\hline 3. Tolerância incipiente & 10 & $\begin{array}{l}\text { 4. Confusão entre espaço público e } \\
\text { privado }\end{array}$ & 6 \\
\hline Há tolerância de alguma maneira & 6 & $\begin{array}{l}\text { Professores são militantes de suas } \\
\text { igrejas na escola }\end{array}$ & 6 \\
\hline Há tolerância porque Deus existe & 1 & & \\
\hline Muitos exercitam a tolerância & 1 & & \\
\hline A tolerância religiosa é uma construção & 1 & & \\
\hline É necessário respeitar o espaço do outro & 1 & & \\
\hline 5. Outros & 4 & & \\
\hline
\end{tabular}

Fonte: Dados da pesquisa, 2017.

Por meio de questões disparadoras como "o que é a tolerância?" e "existe tolerância social?", buscou-se a percepção dos indivíduos sobre o fenômeno, de modo que quatro principais grupos semânticos foram identificados: 1. Inexistência da tolerância 
FREIRE, P.; NASCIMENTO, A. M.

$(n=59), 2$. Necessidade de educação para tolerância $(n=12), 3$. Tolerância incipiente $(n=10)$, 4. Confusão entre espaço público e privado $(n=6)$. A primeira das categorias, Inexistência de tolerância, aponta para sentidos de uma ausência de tolerância nas relações sociais experimentadas:

não existe tolerância [...] existe muita intolerância, as pessoas não respeitam as outras, querem impor uma vontade diferente e as minorias sempre muito descriminadas sofrem muito com a intolerância [...] sendo um preconceito velado, que é o pior que existe, porque tá oculto em você e o indivíduo não deixa transparecer (DADOS DA PESQUISA, 2017).

A segunda categoria mais evocada $(n=12)$, Necessidade de educação para tolerância, delimita uma relação direta, para os respondentes, entre a possibilidade de uma tolerância social e processos educativos. Isso se evidencia por meio de enunciados como:

não estamos preparados para dizer que não temos preconceito, que somos intolerantes. Porque também atravessa a questão do preconceito [...] vai depender também da educação [...] eu volto para a questão da educação, vamos falar na esfera do Brasil, um pais subdesenvolvido... Podemos observar, que os países desenvolvidos investem na educação, enquanto o Brasil não tiver como premissa básica voltada para a educação, vamos ter pessoas intolerantes [...] educação é insuficiente para tolerância, sem educação vamos ter pessoas intolerantes (DADOS DA PESQUISA, 2017).

Considerando a proximidade entre as duas categorias mais salientes, é possível inferir que para os respondentes está estabelecida a percepção de um convívio social intolerante como produto de uma insuficiência educacional.

Uma terceira categoria emergiu a partir das respostas, sendo intitulada, em razão de seu conteúdo, como Tolerância incipiente, informando o sentido da existência de alguma gradação social para a tolerância. Percebeu-se, ainda, uma quarta categoria, Confusão entre espaço público e privado que, embora quantitativamente periférica e por isso não significativa para determinar o conteúdo representacional, traz um sentido partilhado importante para compreensão das questões laicas ao informar a percepção de que interesses privados atravessam a elaboração do espaço público. 
Tabela 3 - Representação sobre o enfrentamento da intolerância

\begin{tabular}{|c|c|c|c|}
\hline Categoria & $f$ & Categoria & $f$ \\
\hline 1. Educação como caminho & 29 & $\begin{array}{l}\text { 2. Impossibilidade de } \\
\text { mudança }\end{array}$ & 26 \\
\hline É possível pela educação & 12 & Difícil mudança & 8 \\
\hline Processo educacional contínuo & 4 & Não haverá mudança & 8 \\
\hline Educação familiar & 4 & $\begin{array}{l}\text { O problema não está na } \\
\text { educação }\end{array}$ & 2 \\
\hline Educação é primordial & 3 & $\begin{array}{l}\text { (A intolerância) é um processo } \\
\text { irreversível }\end{array}$ & 1 \\
\hline Educação inclusiva para tolerância & 3 & $\begin{array}{l}\text { A intolerância é do ser } \\
\text { humano }\end{array}$ & 1 \\
\hline $\begin{array}{l}\text { Tudo começa e termina pela } \\
\text { educação }\end{array}$ & 2 & O Brasil é formado por ladrões & 1 \\
\hline \multirow[t]{5}{*}{ (Mudança) pelo conhecimento } & 1 & Não haverá mudança total & 1 \\
\hline & & (A mudança) é utópico & 1 \\
\hline & & É impossível & 1 \\
\hline & & $\begin{array}{l}\text { Nosso país é totalmente } \\
\text { intolerante, não vamos mudar }\end{array}$ & 1 \\
\hline & & $\begin{array}{l}\text { A tendência é ser mais } \\
\text { intolerante }\end{array}$ & 1 \\
\hline 3. Outros & & & \\
\hline
\end{tabular}

Fonte: Dados da pesquisa, 2017.

A Tabela 3 agrupou os sentidos informados pelos respondentes para a provocação sobre a possiblidade de mudança no quadro de intolerância, o tópico foi disparado a partir das falas que informaram a existência social da intolerância. Partindo dessa provocação, duas categorias emergiram: a. Educação como caminho $(n=29)$ e b. impossibilidade de mudança $(\mathrm{n}=26)$. A primeira delas, veiculando a ideia de possibilidade de enfrentamento, comunica-se com os sentidos já anunciados na Tabela 2 para a percepção da tolerância, a saber, sua conexão com os processos educativos e sua não espontaneidade social. Já a segunda categoria, cuja saliência é apenas ligeiramente inferior a primeira, sugerindo assim uma força equivalente entre as duas categorias, comunica uma impossibilidade de alteração do quadro social de produção da intolerância.

Os conjuntos de sentidos apresentados nas três tabelas configuram, para o grupo de respondentes, as representações elaboradas no cotidiano e socialmente partilhadas sobre laicidade e tolerância, de modo que, em conformidade com a TRS, tais significados orientam as condutas dos indivíduos por serem estes sentidos que informam e explicam suas realidades. É importante destacar o elemento distintivo do grupo em analise, a saber, todos são profissionais da educação pública em posições especificas de poder e atuação. 
Para os respondentes, a laicidade, a separação entre o Estado e as religiões, é um fenômeno meramente formal, existente apenas nos textos legais e distante de suas experiências, sendo exatamente nesse intervalo de não correspondência material que o sentido mais evocado para laicidade emerge (categoria 1 e 2, Tabela 1). Dessa forma, o senso comum partilhado informa que o país é laico, sem haver, contudo, uma experiência laica no cotidiano. No tocante à tolerância, os sentidos se agrupam na direção de uma inexistência social de um ambiente favorável à tolerância (categoria 1, Tabela 2 ) e que essa elaboração estaria relacionada às intervenções educacionais (categoria 2, Tabela 2), de modo que esses sentidos, quando combinados, informam um aspecto pontual para a tolerância, isto é, sua não espontaneidade.

Zarka (2013) propõe uma ampla discussão sobre a tolerância social, qualificandoa como fenômeno não espontâneo, cuja elaboração depende da intervenção dos indivíduos com especial atenção ao papel desempenhado pelo Estado. Já Henri Pena-Ruiz (2003), ao tratar as relações entre laicidade, convívio social e tolerância, assevera serem fenômenos interdependentes, na medida em que somente as sociedades laicas podem produzir ambientes tolerantes, porque os elementos da tolerância seriam, segundo o autor, produto de um convívio igualitário entre cidadãos, sobretudo no tocante à possibilidade de experiência social das liberdades laicas. Para os autores, uma sociedade intolerante estaria relacionada, em algum grau, a ineficácia jurídica e social das disposições laicas, na medida em que indivíduos ou grupos ocupam posições desiguais, gozam privilégios e, a partir destas circunstâncias, restam cerceadas tanto a liberdade de consciência dos que não estão nestas mesmas condições, quanto a possibilidade de reação e produção de contextos de equiparação social, sendo essas tensões entendidas e nomeadas como situações intolerantes.

O descompasso entre a realidade jurídica (eficácia jurídica/dever ser) e a realidade social (efetividade/ser) está presente nos sentidos partilhados (categorias 1, 2, 3 , Tabela 1). No entanto, quando os respondentes afirmam ser laico o Estado, ao passo que a sociedade é intolerante (categorias 1, 2, Tabela 2), resta evidente que os sentidos não são postos como correlatos, ou seja, laicidade e tolerância são significados como fenômenos distintos e dissociáveis, sobretudo quando observada a emergência dos sentidos de formalidade para a laicidade sem que a mesma seja evocada para tolerância. Considerando a teoria das representações sociais, tal dissociação pode orientar os indivíduos no sentido de uma busca por alteração dos quadros de tolerância que não perpasse as questões de laicidade, sobretudo seus três pressupostos, o que resultaria em posturas ineficazes (ZARKA, 2013: PENA-RUIZ, 2003). Isso porque abordar o cenário de intolerância sem que sejam tangenciadas questões de cerceamento da liberdade de consciência e igualdade entre os indivíduos - os dois primeiros pressupostos da laicidade - importa na violação da neutralidade estatal, com efeito, o terceiro pressuposto. Dito de outra forma, quando educadores representam a sociedade como intolerante, ao passo em que consideram o Estado como laico, é provável que ações sejam dirigidas para o enfrentamento do efeito (intolerância) sem o devido tratamento a uma de suas causas (laicidade), por ser esta considerada como algo já posto juridicamente. Desta forma, observa-se uma potencial obstrução das possibilidades de enfrentamento do problema relacionado à dicotomia laicidade-tolerância em razão de sua percepção dissociada.

A respeito dos sentidos partilhados entre os respondentes sobre a possibilidade de mudança no quadro da intolerância, nota-se uma correspondência com a teoria pro- 
posta em Zarka (2013) e Pena-Ruiz (2003), na medida em que evocam a relação entre os processos educativos e as intervenções nos cenários de intolerância (categoria 1, Tabela 3). Todavia, importa destacar que, a partir de suas falas, identificou-se a emergência de sentidos que dão conta da impossibilidade de mudança (categoria 2, Tabela 3), que implica, por sua vez, na possibilidade de uma postura omissa, em razão da descrença na validade interventiva, um dado que deve ser considerado e, ainda mais, quando veiculado por aqueles agentes públicos que são especificamente responsáveis, segundo a teoria, pelas ações de superação da intolerância, a saber: educadores.

A contradição sobre a laicidade, veiculada nos sentidos partilhados pelos educadores respondentes (categorias 1, 2, 3, Tabela 1), quando informam concomitantemente a percepção de uma existência meramente formal para a laicidade e uma inexistência material combinada com um conteúdo social alaico, dá conta de uma hipertrofia simbólica para o ideal laico brasileiro na medida em que o Estado se anuncia laico, inclusive por agentes estatais, mas não fornece instrumentos normativos mínimos para a efetivação da premissa constitucional. Assim, a laicidade simbólica, nos termos postos por Neves $(1996,2011)$, produz um efeito social ideologizante, quando obstrui as possibilidades de enfretamento dos problemas correlatos à temática, o que se observa pelo conteúdo veiculado em todas as categorias presentes na Tabela 2.

Neste ponto, identifica-se a qualidade de legislação simbólica também para a disciplina da LDB infraconstitucional supracitada, ao confrontar suas diretrizes para a educação laica (as questões educacionais atravessadas pelo elemento religioso) e os sentidos dos educadores ouvidos sobre a possibilidade de intolerância nos contextos educacionais, fica evidente a percepção de um contexto intolerante com nítido entrave para elaboração de possibilidades de superação (categorias 1, 2, 3, 4, Tabela 2: categoria 2, Tabela 3).

Como pontua Neves (1996), as constituições e legislações simbólicas são caracterizadas pela obstrução na superação das contradições internas de suas diretrizes normativas. Deste modo, o paradoxo que se estabelece - a partir da fala dos respondentes - em significar a sociedade como laica formalmente e socialmente alaica e intolerante, configuram os sentidos sobre a laicidade e tolerância como indicativos de uma laicidade simbólica que impede os atores sociais implicados de vislumbrar alternativas diferentes daquelas por eles experimentadas.

Nisso, a laicidade simbólica (Tabela 1), ainda segundo Neves (2011), é do tipo confirmação de valores e legislação-álibi, ao produzir um contexto social intolerante a partir de interesses de grupos específicos e deslocar a responsabilidade por tais circunstancias do Estado para situações não sabidas. Assim, a laicidade simbólica é corroborada pelos sentidos identificados para as questões de tolerância, sendo de primeiro tipo, em razão dos sentidos observados nas categorias 1 e 4 da Tabela 2, que informam traços específicos da intolerância comunicados pelos respondentes, marcada pela imposição de interesses de uma maioria religiosa sobre as demais minorias, determinando uma relação de desigualdade entre cidadãos de modo explícito ou velado. Identifica-se ainda a utilização, por outros educadores, do espaço público como meio de promoção de conteúdos religiosos, sendo estes os traços próprios ao simbolismo que seleciona indevidamente valores de um grupo sobre todos os demais, através de recursos 
FREIRE, P.; NASCIMENTO, A. M.

legitimadores estatais, como a educação. Já o segundo tipo, legislação-álibi, evidencia-se quando os educadores respondentes não compreendem a si mesmos como protagonistas da mudança evocada, mesmo quando afirmam ser a educação o instrumento de superação da intolerância (categoria 1, Tabela 3) ou quando significam em paralelo a intolerância como uma experiência insuperável (categoria 2, Tabela 3).

Em tempo, a laicidade configura-se ainda como uma normatividade álibi e confirmadora de valores, ao pontuar uma série de signos jurídicos para as liberdades laicas e para uma educação laica. Entretanto, opera o Estado no cotidiano a manutenção de contextos excludentes a partir da seleção dos valores privados de cunho religioso que decide promover, veladamente ou não, excluindo da experiência social os sentidos de laicidade e tolerância que, a despeito de presentes na norma, são ausentes na realidade social e mantidos assim pelas estruturas de poder reforçadas por essa mesma normatividade simbólica.

\section{CONSIDERAÇÕES FINAIS}

Iniciou-se o presente estudo com uma abordagem que trata das teorias da constitucionalização simbólica, da laicidade e tolerância, enfrentando-se ainda, brevemente, a normativa nacional vigente para os processos educacionais. Seguiu-se com a exposição e discussão dos dados, quando se encaminhou, finalmente, a triangulação entre dados e teorias, possibilitando estas considerações.

Por meio da análise de todo o material coletado, foi possível concluir que os respondentes representam a laicidade e a tolerância como fenômenos dissociados, entendendo a laicidade como existente, com status de fenômeno jurídico-formal, sem um correspondente social concreto, enquanto a tolerância é significada como socialmente inexistente. Emergem ainda sentidos de possibilidade e impossibilidade de uma reelaboração da tolerância social pela via educacional, sem, contudo, estarem eles, enquanto educadores, implicados nesse processo. Dessa forma, observa-se, a partir dos sentidos contraditórios apreendidos, a qualidade simbólica da laicidade, nas modalidades confirmação de valores e legislação-álibi, configurando-se como óbice para a superação dos contextos de intolerância social marcada pelo elemento religioso.

Levando em conta que a atual pesquisa não possui caráter generalizante, destaca-se a necessidade de novos estudos, para uma abordagem mais abrangente sobre o tema, de modo que se analise a necessidade de implementação de políticas públicas voltadas ao enfrentamento do quadro de simbolismo laico e contextos de intolerância identificados nos dados da atual pesquisa e para além deles, nas diversas dinâmicas socialmente observáveis. 


\title{
LAITY, TOLERANCE AND EDUCATION: A STUDY ON TEACHERS' SOCIAL REPRESENTATIONS IN THE PUBLIC SCHOOL SYSTEM IN A MUNICIPALITY IN THE INTERIOR OF PERNAMBUCO
}

\begin{abstract}
The present article aims to analyze the perception of teachers in public schools about secularity, with a view to discussing the experience of public space and how social tolerance is built from these symbolic exchanges. As a collection instrument, a semi-structured script was used, and the thematic content analysis was used to evaluate the material. It was concluded that respondents represent secularity and tolerance as dissociated phenomena, understanding secularity as existing, with status as a legal-formal phenomenon, without a concrete social correspondent, while tolerance is signified as socially non-existent, becoming secularity in a symbolic norm in the modalities of confirmation of values and legislation-alibi, configuring as an obstacle to overcoming the contexts of social intolerance marked by the religious element.
\end{abstract}

KEYWORDS: Laicity. Public education. Symbolic constitutionalism. Social representations.

\section{LAICIDAD, TOLERANCIA Y EDUCACIÓN: UN ESTUDIO SOBRE REPRESENTACIONES SOCIALES DE PROFESORES EN LA RED PÚBLICA EN UN MUNICIPIO EN EL INTERIOR PERNAMBUCANO}

RESUMEN: El presente artículo objetiva analizar la percepción de profesores en escuelas públicas sobre la laicidad, con vistas a discutir la experiencia del espacio público y cómo se construye la tolerancia social a partir de esos intercambios simbólicos. Como instrumento de recolección, se utilizó un guión semiestructurado, siendo adoptada el análisis de contenido temático para la apreciación del material. Se concluyó que los respondedores representan la laicidad y la tolerancia como fenómenos disociados, entendiendo la laicidad como existente, con status de fenómeno jurídico-formal, sin un correspondiente social concreto, mientras que la tolerancia es significada como socialmente inexistente, convirtiéndose la laicidad en norma simbólica en las modalidades confirmación de valores y legislación-coartada, configurándose como obvio para la superación de los contextos de intolerancia social marcada por el elemento religioso.

PALABRAS CLAVE: Laicidad. Enseñanza pública. Constitucionalismo simbólico. Representaciones sociales.

\section{NOTAS}

1) O interesse da Igreja Católica pelo ensino público é um traço milenar da instituição. Sendo a celebração de acordos bilaterais entre Igreja e estados uma prática reiterada desde o início da modernidade. Diversos países no ocidente firmaram tais tratados, com vistas a outorgar à Igreja o poder de interferência nos processos educacionais destas respectivas nações. Diversos autores consideram tal fenômeno jurídico como um instrumento de frontal violação da laicidade. Vide: Catroga, F., Entre deuses e Césares: secularização, laicidade e religião civil, uma perspectiva histórica, 2010, p.231 e s.; Freire, P. Laicidade Ficta, Democracia Urgente, 2017, p. 31 e s. 
FREIRE, P.; NASCIMENTO, A. M.

\section{REFERÊNCIAS}

BARDIN, L. Análise de conteúdo. Lisboa: Edição 70, 2002.

BARROSO, L. R. O direito constitucional e a efetividade de suas normas: limites e possibilidades da Constituição brasileira. 5. ed. Rio de Janeiro: Renovar, 2001.

BLANCART, R. O porquê de um Estado laico. In: LOREA, R. A. (Org.). Em defesa das liberdades laicas. Porto Alegre: Livraria do Advogado Editora, 2008.

BRASIL. Constituição da República Federativa do Brasil de 1988. Brasília, DF: Presidência da República, 1988. Disponível em:

http://www.planalto.gov.br/ccivil_03/constituicao/ConstituicaoCompilado.Htm. Acesso em: 10 fev. 2017.

BRASIL. Lei no 9.394, de 20 de dezembro de 1996. Estabelece as diretrizes e bases da educação nacional. Brasília, DF: Presidência da República, 1996. Disponível em: http://www.planalto.gov.br/ccivil_03/LEIS/L9394.htm. Acesso em: 10 fev. 2017.

CATROGA, F. Entre deuses e Césares. 2. ed. Coimbra: Almedina, 2010.

FARIA, A. C. C.; PEREIRA, J. H. de O. S. Acordo entre Brasil e Santa sé: um marco na relação Igreja-Estado no Brasil. 2012. Disponível em: http://www.pucrio.br/pibic/relatorio_resumo2012/relatorios_pdf/ccs/DIR/JURJairo\%20Henrique\%20de\%200.S.\%20Pereira.pdf . Acesso em: 15 mar. 2017.

FREIRE, P. Laicidade ficta, democracia urgente. 1. ed. Rio de Janeiro: Lumen Juris, 2017.

GUSTIN, M. B. de S.; DIAS, M. T. F. (Re)pensando a pesquisa jurídica: teoria e prática. 4.ed. rev. e atual. Belo Horizonte. Del Rey, 2013.

JODELET, D. As representações sociais. Tradução Lilian Ulup. Rio de Janeiro: EdUERJ, 2001.

LANE, Silvia T. M. Consciência/ alienação: a ideologia no nível individual. In: S. T. M. Lane, S. T. M.; CODO, W. (Org.). Psicologia social: o homem em movimento. São Paulo: Brasiliense. 1989.

NEVES, M. Constitucionalização simbólica e desconstitucionalização fática: mudança simbólica da Constituição e permanência das estruturas reais de poder. Revista de informação legislativa, 1996. Disponível em:

http://www2.senado.leg.br/bdsf/item/id/176514. Acesso em: 14 out. 2017.

NEVES, M. A constitucionalização simbólica. São Paulo: Wmf Martins Fontes, 2011.

PENA-RUIZ, H. Qu'est-ce que la laïcité?, Paris: Gallimard, 2003. 
SÁ, C. P. A construção do objeto de pesquisa em representações sociais. Rio de Janeiro: EdUERJ, 1998.

SANTOS, M. de F. S.; ALMEIDA, L. M. Diálogos com a teoria da representação social. Pernambuco: Ed. Universitária da UFPE, 2005.

ZARKA, C. Y. Difícil tolerância. São Leopoldo: Unisinos, 2013.

Phablo Freire: Professor universitário, advogado, Mestre em Psicologia Social pelo Programa de Pós-Graduação em Psicologia da Universidade Federal do Vale do São Francisco (UNIVASF), Pós-graduado em Gestão Pública pela Faculdade de Ciências Aplicadas e Sociais de Petrolina (FACAPE) e em Direito Constitucional Aplicado pela Damásio Educacional e Docente do Colegiado de Direito da Faculdade de Ciências Humanas e Exatas do Sertão do São Francisco (FACESF).

ORCID: https://orcid.org/0000-0001-7005-7721

E-mail: phablo-freire@hotmail.com

Amanda Matos do Nascimento: Bacharela em Direito pela Faculdade de Ciências Aplicadas e Sociais de Petrolina (FACAPE).

ORCID: https://orcid.org/0000-0003-0381-1581

E-mail: amandamatos092@gmail.com

Este periódico utiliza a licença Creative Commons Attribution 3.0, para periódicos de acesso aberto (Open Archives Iniciative - OAI). 